\title{
Vibrations of the TAIPEI 101 skyscraper caused by the 2011 Tohoku earthquake, Japan
}

\author{
Kou-Cheng Chen, Jeen-Hwa Wang, Bor-Shouh Huang, Chun-Chi Liu, and Win-Gee Huang \\ Institute of Earth Sciences, Academia Sinica, P.O. Box 1-55, Nankang, Taipei 11529, Taiwan
}

(Received December 27, 2011; Revised March 26, 2012; Accepted April 8, 2012; Online published January 28, 2013)

\begin{abstract}
The strong-motion recordings generated by the 11 March 2011, Tohoku, Japan earthquake recorded by the building seismic array in the TAIPEI 101, the second tallest building in the world, are more complicated than those at the free-field stations. Fundamental and higher-mode vibrations can be clearly seen on the spectra. The fundamental-mode frequency is about $0.15 \mathrm{~Hz}$, which is the natural frequency of the skyscraper. Spectral ratios of ground accelerations at the building to those at a nearby borehole station increase from unity at the fifth floor underground to factors of 110 and 146 , respectively, on the $74^{\text {th }}$ and $90^{\text {th }}$ floors above ground for the fundamental-mode vibrations. The frequency content of accelerograms, recorded on the fifth floor below ground from the great 2011 Tohoku-Oki earthquake, appears mainly in a frequency band of $0.015-0.1 \mathrm{~Hz}$, leading to a fact that the ground motions did not cause high excitation in the TAIPEI 101 skyscraper.
\end{abstract}

Key words: Building array, TAIPEI 101, vibration, Tohoku earthquake.

\section{Introduction}

The great Tohoku-Oki earthquake $\left(M_{\mathrm{w}} 9.0\right)$ of 11 March, 2011 occurred off the northeast coast of Japan, resulting from slip on a roughly 500-km-long and 200-km-wide megathrust fault (e.g., Lee et al., 2011; Suzuki et al., 2011). This earthquake caused tremendous damage in northern Japan due to extensive tsunami as well as strong shaking. This earthquake resulted in 15,550 fatalities, 5,344 missing, 5,688 injured, 224,798 houses collapsed and more than 460,000 houses damaged (Tsuru and Murakami, 2011).

Strong ground motions generated from the 2011 Tohoku earthquake were well recorded by nearly 1200 K-NET and KiK-net stations across Japan, with a peak ground acceleration as large as $2933 \mathrm{gal}$ at MYG004 and more than $1 \mathrm{~g}$ at 10 sites (Aoi et al., 2011). From snapshots of seismic wave propagation of the strong ground motion during the earthquake, Furumura et al. (2011) observed the amplified and prolonged ground shaking in some populated cities due to the resonance of long-period ground motions within sedimentary basins. They also found that the 2011 Tohoku earthquake generated a large response in a relatively wide period ranging from 0.5 to $30 \mathrm{sec}$, resulting in a significant impact on many wooden-frame houses to high-rise buildings. Several high-rise buildings in Tokyo, about 370 $\mathrm{km}$ from the epicenter, swept but did not have any significant damage during the great 2011 Tohoku-Oki earthquake. However, the tip of Tokyo Tower was bent by the strong shaking of the earthquake.

The great 2011 Tohoku-Oki earthquake was also well recorded by the TAIPEI 101 building seismic array, about

Copyright (C) The Society of Geomagnetism and Earth, Planetary and Space Sciences (SGEPSS); The Seismological Society of Japan; The Volcanological Society of Japan; The Geodetic Society of Japan; The Japanese Society for Planetary Sciences; TERRAPUB.

doi:10.5047/eps.2012.04.004
2,500 $\mathrm{km}$ from the epicenter (Fig. 1). TAIPEI 101 is the second tallest building in the world. Strong ground motion generated from this earthquake will provide valuable information to study the earthquake-induced effects on vibrations of this kind of super tall high-rise building. Chen (2003) reported that a distant earthquake $\left(M_{\mathrm{w}} 7.0\right)$ in 2002 caused two massive construction cranes on TAIPEI 101 to fall from the $56^{\text {th }}$ floor to the ground while it was under construction. However, no any seismic instrument was installed in this building at that time. In this study, strong ground motions recorded at the TAIPEI 101 building array and a nearby downhole broadband seismometer (denoted by 101B), which is located at a distance of about $500 \mathrm{~m}$ from the TAIPEI 101 skyscraper and the sensor is installed at a depth of $100 \mathrm{~m}$, were analyzed to investigate vibrations of the high-rise building caused by the great 2011 Tohoku-Oki earthquake. This study will be of interest not only to seismologists but also to building engineers for the construction of super tall skyscrapers and the safety of building occupants and contents.

\section{Data Collection}

TAIPEI 101 is located at the Hsinyi District of Taipei, Taiwan (Fig. 2). The building is comprised of 101 floors above ground and five floors below ground (Haskett et al., 2003; Shieh et al., 2003; Joseph et al., 2006). The height of the main building is $455 \mathrm{~m}$, atop of which is a spire that gives the building a total height of $508 \mathrm{~m}$. The building is equipped with three tuned mass dampers (TMDs) (Haskett et al., 2003). The first is a 660-metric-ton ball installed between the $87^{\text {th }}$ and $91^{\text {st }}$ floors and observable from public viewing platforms on the $88^{\text {th }}$ and $89^{\text {th }}$ floors. The second and third lesser TMDs are both 4.5 metric tons and provide passive motion dampening in the spire. The TMDs function to reduce vibrations caused by earthquakes and ty- 


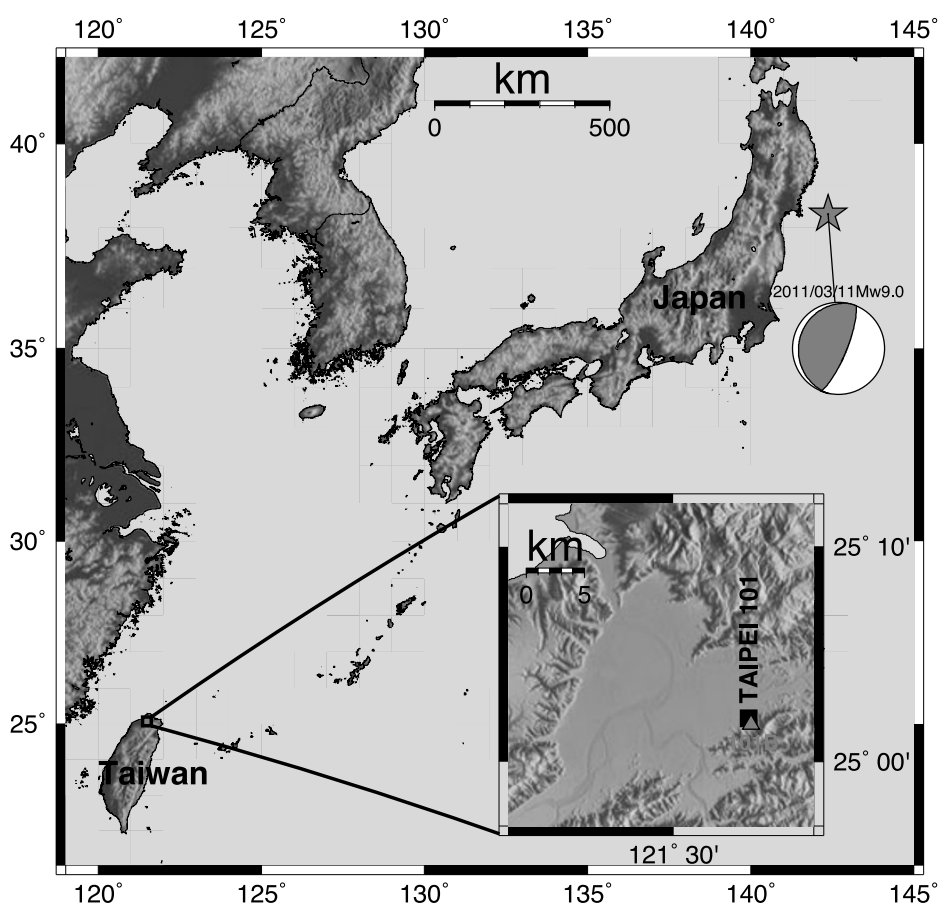

Fig. 1. Epicenter and focal mechanism of the 11 March 2011, Tohoku, Japan earthquake. The red square marks the city of Taipei. The insert shows locations of the TAIPEI 101 skyscraper (solid square) and broadband downhole station (triangle).

phoons (Haskett et al., 2003). Taiwan is particularly prone to both. Since July 2010, the Institute of Earth Sciences (IES), Academia Sinica has operated a building array at TAIPEI 101 (denoted by TBA) to routinely record building vibrations and to monitor the effects of typhoon-force winds and earthquakes on the building.

The TBA consists of four stations: two pairs of force balance accelerometer and R-1 rotational seismometer emplaced, respectively, in the southwest (T1S3 and T1S3R) and northeast corners of the $90^{\text {th }}$ floor (T1S4 and T1S4R); and another two pairs of force balance accelerometer and broadband velocity sensor emplaced in the southwest corner of $74^{\text {th }}$ floor and the fifth floor below ground (T1S2 and T1S1), respectively. The frequency range of the accelerometer is from $\mathrm{DC}$ to $200 \mathrm{~Hz}$ and has the ability to record shaking level as high as $2 \mathrm{~g}$. The broadband velocity sensor is capable of measuring ground-motion up to $20 \mathrm{~cm} / \mathrm{sec}$ with a bandwidth from $0.008 \mathrm{~Hz}$ to $70 \mathrm{~Hz}$. All of the stations record signals continuously at 100 and 20 samples per second, respectively. Time synchronization is maintained in the main processor based on time received according to the NTP (network time protocol) through communication with an internet time server. The R-1 rotational seismometer has a resolution of $1.2 \times 10^{-7} \mathrm{rad} / \mathrm{sec}$ (eentec, 2007). The sensitivities of the velocity and acceleration sensors are $2.384 \times 10^{-5} \mathrm{~cm} / \mathrm{sec} /$ count (Hutt et al., 2008) and $2.337 \times 10^{-4} \mathrm{~cm} / \mathrm{sec}^{2} /$ count (Kinemetrics, 2002), respectively. The downhole broadband station (101B) is located at a distance of about $500 \mathrm{~m}$ from the TAIPEI 101 skyscraper and the sensor is installed at a depth of $100 \mathrm{~m}$ (Huang et al., 2010).

\section{Vibration of the Taipei 101 Skyscraper}

Figure 2(b) shows the N-S component seismograms recorded at T1S1, T1S2, T1S3, T1S4, and 101B. The maximum values of peak ground accelerations (PGA) in the N-S direction on the fifth floor below ground and the $74^{\text {th }}$ floor were 0.253 and $0.74 \mathrm{~cm} / \mathrm{sec}^{2}$, respectively. The PGA values on the $90^{\text {th }}$ floor were about four times of those on the fifth floor below ground. It is noted that seismograms recorded at the TBA are more complicated than those at station 101B. The main building's TMD with a gross weight of 660 metric tons did not sway during the earthquake.

To retrieve significant information recorded by the TBA, DC-offset is first eliminated by subtracting the mean amplitude from raw data. The Fourier amplitude spectra were calculated and smoothed using a 3-point running Hanning average. Fifty consecutive smoothing processes were applied to the raw spectra. This number was chosen empirically considering its visual effect on the spectral shape. In order to obtain the same scale, velocity spectra at 101B were multiplied by the angular frequency to produce the acceleration spectra. Figure 2(c) shows the acceleration spectra along the N-S component on the $90^{\text {th }}$ floor and the station 101B. Spectral amplitudes on the $90^{\text {th }}$ floor show several local peak amplitudes at different frequencies, while those at station 101B gradually decrease with increasing frequency.

The acceleration spectra in the frequency range from 0.01 to $8 \mathrm{~Hz}$ along three components are demonstrated in Fig. 3. When $f<0.1 \mathrm{~Hz}$, the spectral amplitudes (about $200 \mathrm{~cm} / \mathrm{sec}$ ) at the stations on different floors in the building and those at station 101B are almost identical. When $f>0.1 \mathrm{~Hz}$, spectral amplitudes at the stations in the building are different from those at station 101B. For the stations on the fifth floor underground and station 101B, the spectral patterns along three components are very similar, 


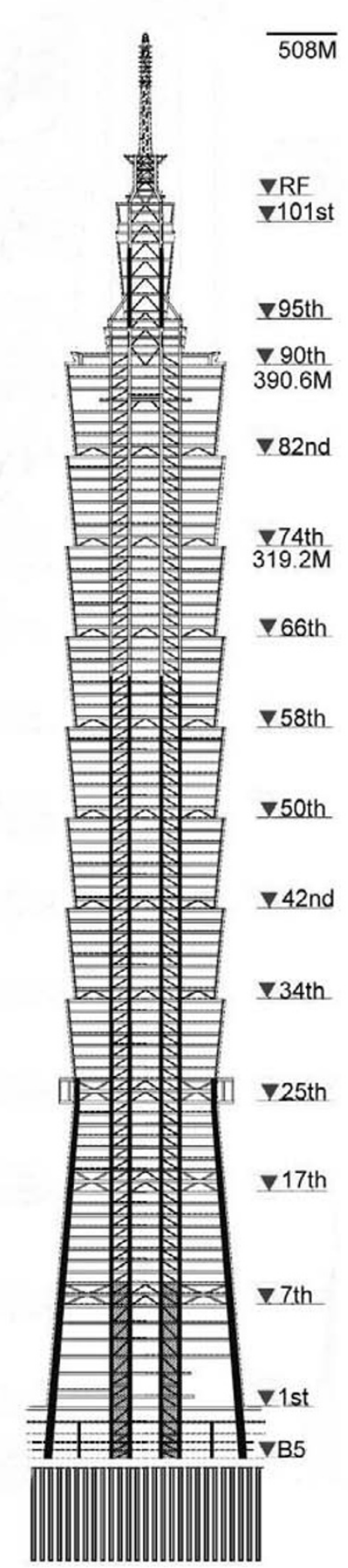

(a)
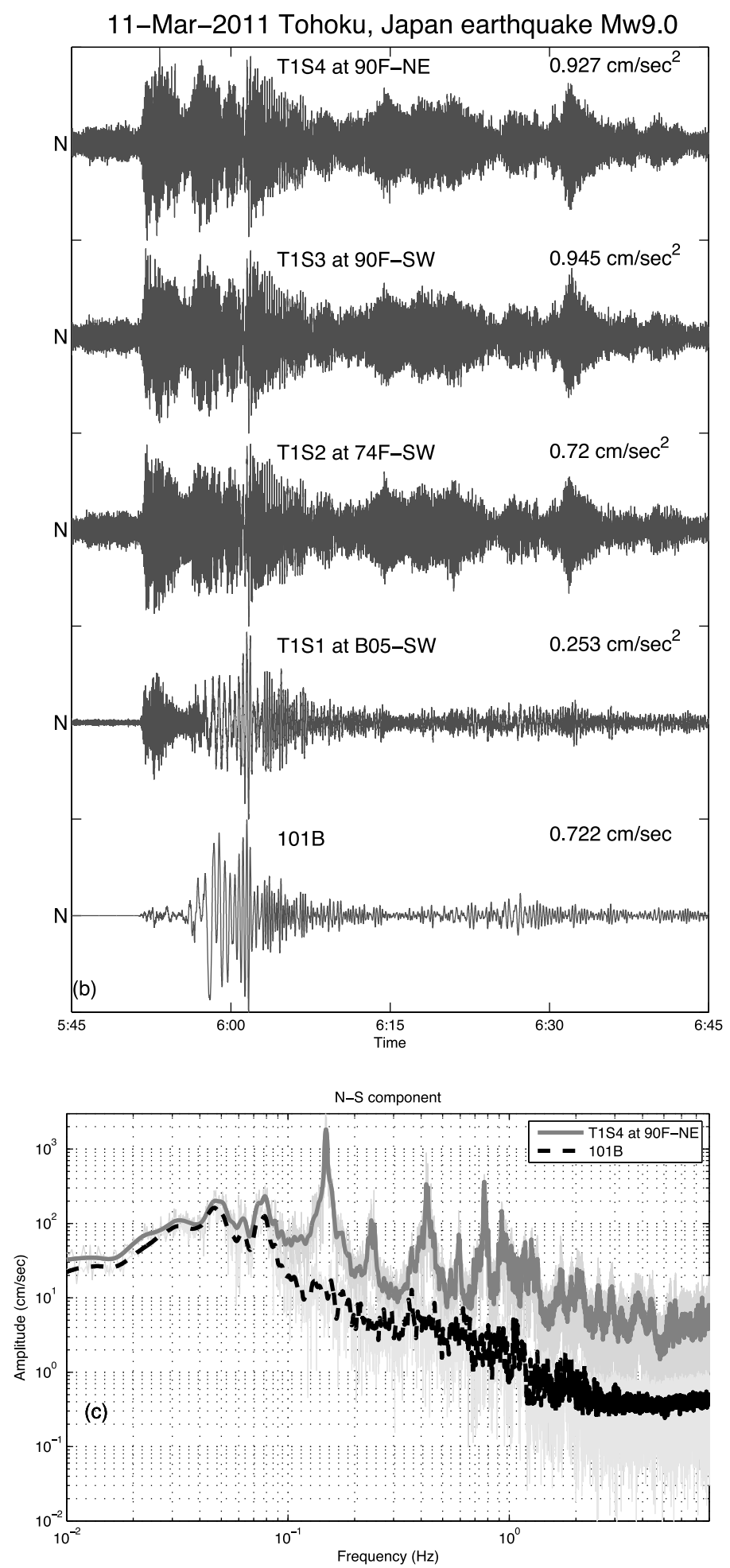

Fig. 2. (a) Sketch of the TAIPEI 101 (redrawn from Shieh et al., 2003). (b) Strong-motion recordings of the 11 March 2011, Tohoku, Japan earthquake recorded by the TAIPEI 101 building seismic array at T1S1 on the fifth floor underground, at T1S2 on the $74^{\text {th }}$ floor, at T1S3 and T1S4 on the $90^{\text {th }}$ floor, and at 101B broadband downhole station. (c) Spectral amplitudes for the N-S component at T1S4 and 101B.

except for a fact that the spectral amplitudes at the former are larger than those at the latter at $f=\sim 1 \mathrm{~Hz}$. For the stations on the $74^{\text {th }}$ and $90^{\text {th }}$ floors, the local peak amplitudes along the three components at related frequencies can be clearly delineated. In spite of the differences in amplitudes, the frequencies with the local peak amplitudes are almost identical along the three components. The maximum horizontal spectral amplitudes appear at $f_{0}=0.15 \mathrm{~Hz}$, which is almost the natural frequency of the skyscraper (Haskett $e t$ al., 2003). The higher-mode vibrations below $1.5 \mathrm{~Hz}$ appear at $f_{1}=0.24 \mathrm{~Hz}, f_{2}=0.43 \mathrm{~Hz}, f_{3}=0.59 \mathrm{~Hz}, f_{4}=0.78$ $\mathrm{Hz}, f_{5}=1.05 \mathrm{~Hz}$, and $f_{6}=1.26 \mathrm{~Hz}$. The higher modes 

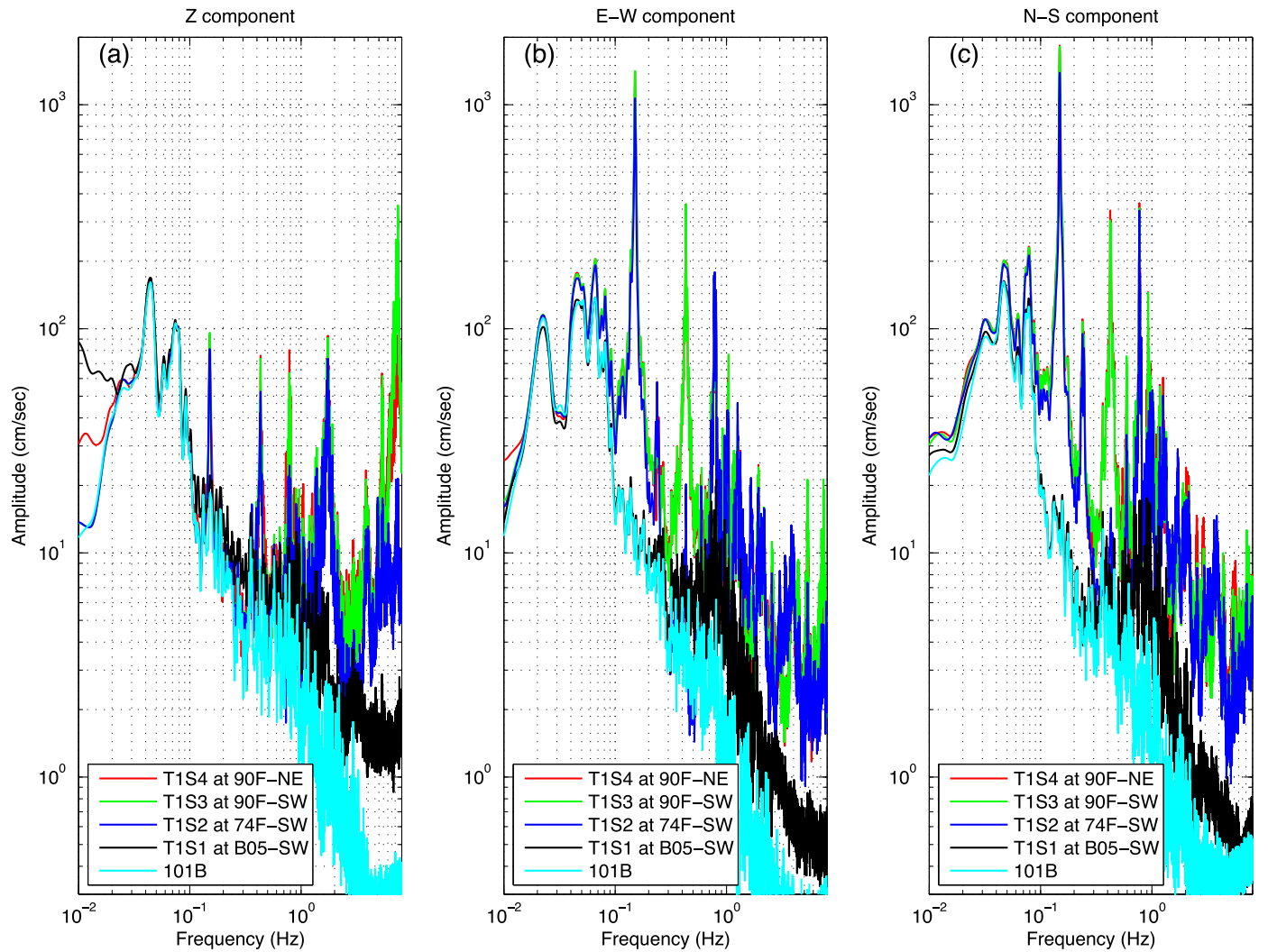

Fig. 3. Spectral amplitudes of the 11 March 2011, Tohoku, Japan earthquake: (a) for the $Z$ component, (b) for the E-W component, and (c) for the N-S components. The spectra at different stations are shown by lines with distinct colors.
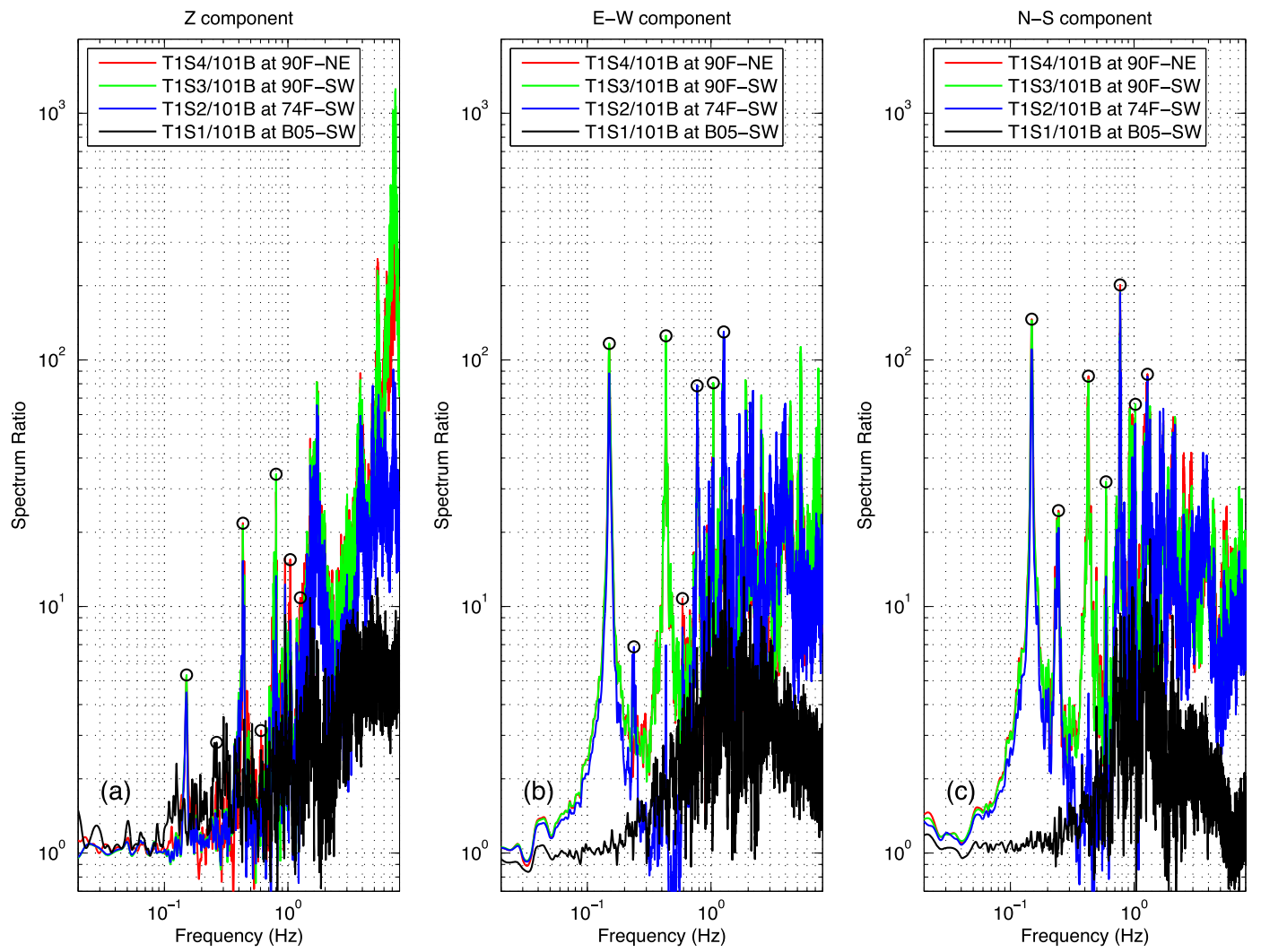

Fig. 4. Spectral ratios of building vibrations: (a) for the $Z$ component, (b) for the E-W component, and (c) for the N-S components. The spectra at different stations are shown by lines with distinct colors. Several vibration modes with the local peak amplitudes are denoted by open circles. 
Table 1. The values of $f_{0}, f_{i}(i=0,1,2, \ldots, 6)$, and the ratios of $A_{Z i}, A_{\mathrm{EW} i}$, and $A_{\mathrm{NS} i}$ for the $Z$-, EW-, and NS-components.

\begin{tabular}{|l|c|c|c|c|c|r|}
\hline \multirow{2}{*}{$i$} & \multicolumn{2}{|c|}{$Z$-component } & \multicolumn{2}{c|}{ EW-component } & \multicolumn{2}{c|}{ NS-component } \\
\cline { 2 - 7 } & $f_{i}$ & $A_{Z i}$ & $F_{i}$ & $A_{\mathrm{EW} i}$ & $f_{i}$ & $A_{\mathrm{NS} i}$ \\
\hline 0 & 0.15 & 5.27 & 0.15 & 116.5 & 0.15 & 146.3 \\
1 & 0.26 & 2.81 & 0.24 & 6.9 & 0.25 & 24.5 \\
2 & 0.43 & 21.8 & 0.43 & 125.2 & 0.43 & 86.0 \\
3 & 0.61 & 3.1 & 0.59 & 10.8 & 0.59 & 32.0 \\
4 & 0.80 & 34.4 & 0.77 & 78.5 & 0.77 & 201.5 \\
5 & 1.04 & 15.5 & 1.05 & 80.8 & 1.03 & 66.0 \\
6 & 1.26 & 10.8 & 1.27 & 129.9 & 1.28 & 87.5 \\
\hline
\end{tabular}
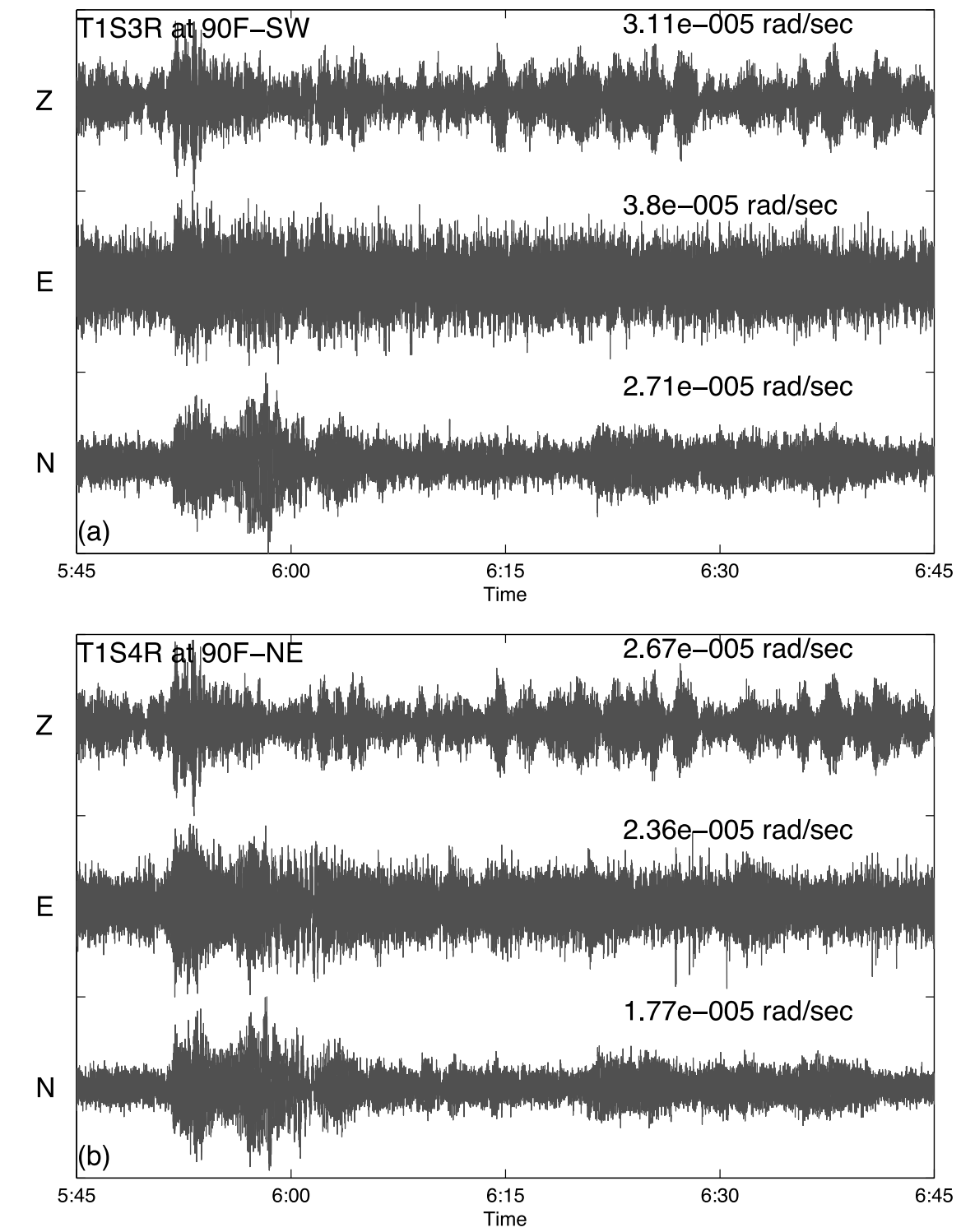

Fig. 5. Rotational motions of the TAIPEI 101 skyscraper (a) at the southwest corner and (b) at the northeast corner of the $90^{\text {th }}$ floor induced by the 11 March 2011, Tohoku, Japan earthquake $\left(M_{\mathrm{w}}=9.0\right)$.

with $f>1.5 \mathrm{~Hz}$ cannot be easily delineated.

Figure 4 shows ratios of spectral amplitudes on the different floors to those at station 101B. The downhole broadband station (101B) is taken to be a reference station in this study, because there is no free surface station near the TAIPEI 101 skyscraper. The spectral ratios (denoted here by $\mathrm{T} 1 \mathrm{~S} 1 / 101 \mathrm{~B}$ ) between the fifth floor below ground at a depth of $20 \mathrm{~m}$ and station $101 \mathrm{~B}$ at a depth of $100 \mathrm{~m}$ are smaller than 2 when $f<0.3 \mathrm{~Hz}$ and are up to about 10 at $f=\sim 1 \mathrm{~Hz}$. This could be due to amplifications of vibrations in the soft surface layers. The spectral ratios for seven local peak amplitudes along the three components at related frequencies are displayed in Table 1. For the fundamentalmode vibration at $f_{0}=0.15 \mathrm{~Hz}$ on the N-S component, spectral ratios increase from unity on the fifth floor underground to factors of 110 and 146 , respectively, on the $74^{\text {th }}$ 

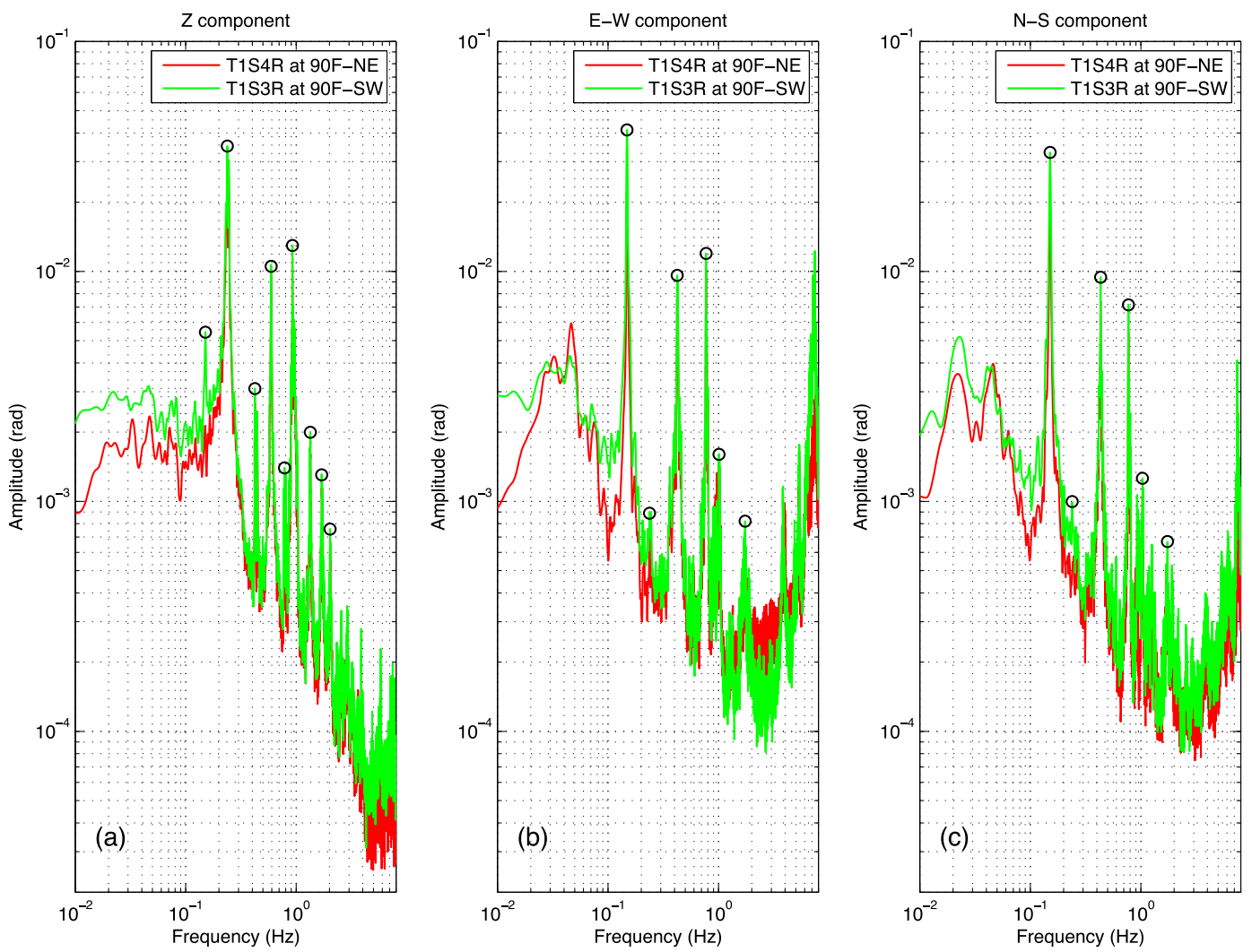

Fig. 6. Spectral amplitudes of rotation motion from the 11 March 2011, Tohoku, Japan earthquake: (a) for the $Z$ component, (b) for the E-W component, and (c) for the N-S components. The spectra at different stations are shown by lines with distinct colors. Several vibration modes with the local peak amplitudes are denoted by open circles.

and $90^{\text {th }}$ floors above ground.

When buildings are subjected to earthquake ground shaking, torsional (rotational) vibration (rotation about the vertical axis) will be produced in addition to translational vibration. Figure 5 shows rotational motions of the TAIPEI 101 skyscraper at the southwest and northeast corners of the $90^{\text {th }}$ floor induced by the earthquake. The rotational motions along three components were larger at the southwest corner of the $90^{\text {th }}$ floor (T1S3R) than at the northeast (T1S4R). The maximum rotational motion was about $3.8 \times 10^{-5} \mathrm{rad} / \mathrm{sec}$ on the EW component at station T1S3R. The rotational motions (Fig. 5) during earthquake shaking were relatively low in comparison with the translational motions (Fig. 2(b)).

The spectral amplitudes of rotational motions in the frequency range from 0.01 to $8 \mathrm{~Hz}$ along the three components at the two stations are showed in Fig. 6. The spectral patterns of rotational motions along the three components were very similar, except for a fact that the spectral amplitudes at T1S3R were larger than those at T1S4R. The local peak amplitudes along the three components at related frequencies can be clearly delineated. The maximum horizontal spectral amplitudes appear at $f_{0}=0.15 \mathrm{~Hz}$, which is almost the natural frequency of the skyscraper (Haskett et al., 2003). For the torsional vibration as shown in Fig. 6(a), the maximum spectral amplitude appears at $f=0.24 \mathrm{~Hz}$, which is the fundamental mode of torsional vibration. It is noted that a smaller spectral amplitude of torsional vibration appears at $0.15 \mathrm{~Hz}$, which is consistent with the fundamental mode of translational vibration. In spite of the differences in amplitudes, the torsional frequencies with the local peak amplitudes appear at $0.15,0.24,0.42,0.59,0.78,0.92$, and $1.34 \mathrm{~Hz}$

\section{Discussion}

In Fig. 3, several major vibration modes, associated with respective local peak amplitudes, can be delineated. The frequencies with local peak amplitudes may be closely associated with the vibrations of the TAIPEI 101 skyscraper caused by the earthquake. The maximum spectral value appears at $f_{0}=0.15 \mathrm{~Hz}$, which is the frequency of fundamental mode and also the natural frequency (or the natural period of $6.8 \mathrm{sec}$ ) of the building TMD (Haskett et al., 2003), for the three components at T1S2, T1S3, and T1S4. The spectral amplitudes along the three components at T1S1 are much smaller than those at T1S2, T1S3, and T1S4. This indicates that ground motions in the high-rise building are much larger than those on the basement. The horizontal spectral amplitudes are larger than the vertical ones when $f<1 \mathrm{~Hz}$. This might be due to a fact that the loading forces on the building caused by the earthquake are mainly along horizontal direction, especially in the lower frequency regime. For the vertical component, the spectral amplitudes at T1S3 and T1S4 are much larger than those at T1S2, T1S1, and 101B when $f>2 \mathrm{~Hz}$. The frequency content of accelerograms recorded on the fifth floor below ground appears mainly in a frequency band of $0.015-0.1$ $\mathrm{Hz}$ (see Fig. 3). This observation explains why the ground motions did not cause much response in the TAIPEI 101 


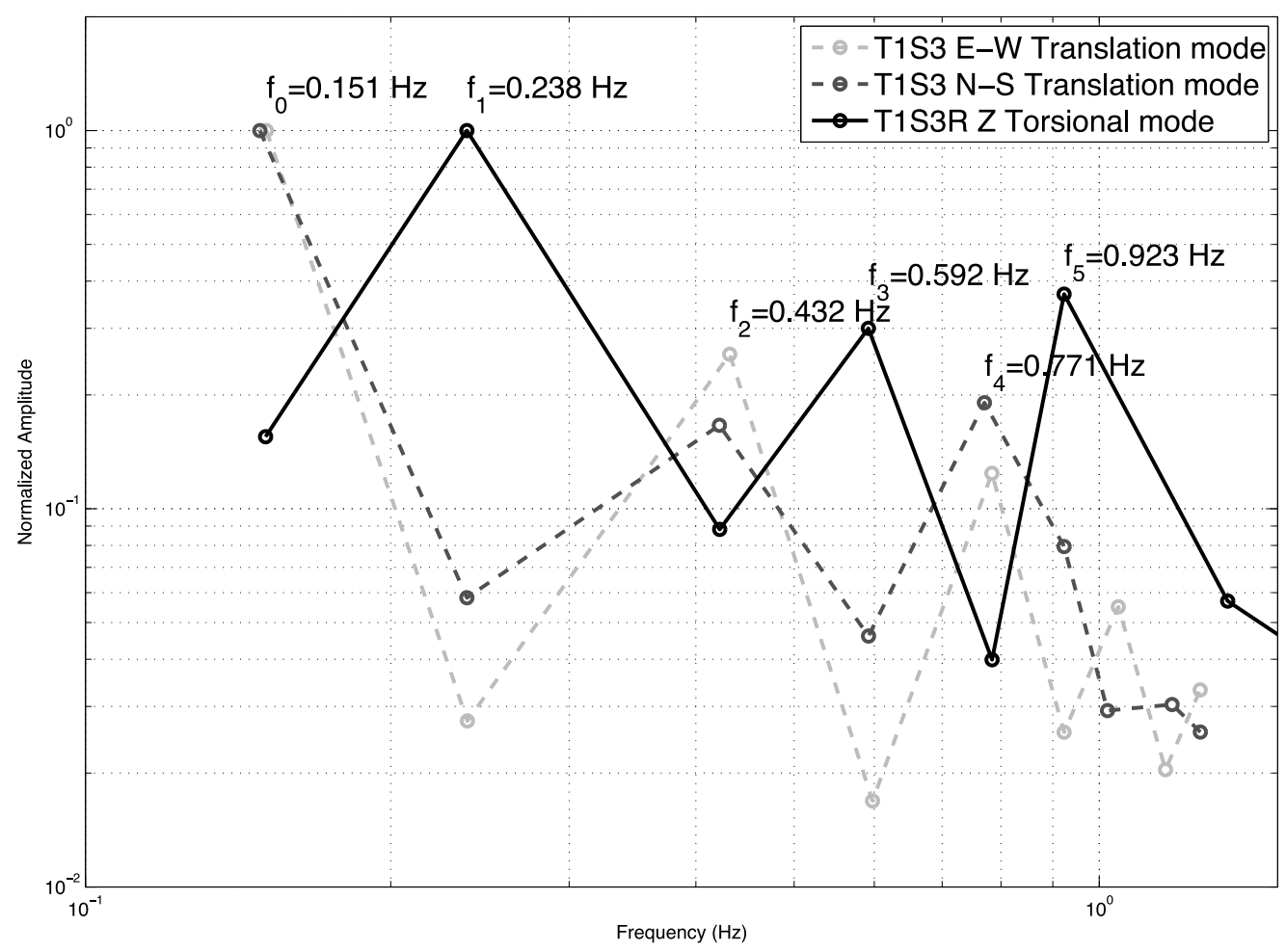

Fig. 7. Variation of the normalized peak amplitudes for the translational (T1S3) and torsional (T1S3R) modes at the southwest corner of the $90^{\text {th }}$ floor.

skyscraper.

The spectral amplitudes of higher-mode vibration should be smaller than those of fundamental-mode vibration, and decrease with increasing frequency. However, the observed spectral amplitudes change with frequency as shown in Figs. 3 and 6. The vibrations observed might be the combination of translational and torsional vibrations. For the TAIPEI 101 skyscraper with 101 stories, the building has 202 translational modes and 101 torsional modes. The two building modes might be coupled (a mode that has motion contributed by other orthogonal directions) or completely uncoupled. Only the first few building modes are discussed in this study. For the fundamental building mode, the maximum spectral amplitudes of translational motions on the two horizontal components (Figs. 3(b) and 3(c)) and a small spectral amplitude of rotational motions on the vertical component (Fig. 6(a)) appear at $f_{0}=0.15 \mathrm{~Hz}$. This indicates that the fundamental mode shows a translational vibration along the horizontal components with a small rotational vibration. On the contrary, the second mode at $f=$ $0.24 \mathrm{~Hz}$ (Fig. 6(a)) is the fundamental mode of torsional vibration with a small translational vibration (Fig. 3(b) and $3(c)$ ). Figure 7 shows the variations of normalized peak amplitudes for the translational (T1S3) and torsional (T1S3R) modes at the southwest corner of the $90^{\text {th }}$ floor. It is noticed that in the first six modes, the peak frequencies obtained from spectral amplitudes of accelerations and rotational motions are very close to each other but the peak amplitudes are reversely related to each other in each pair of modes. Therefore, both the translational and torsional vibrations of the TAIPEI 101 skyscraper can be observed either from spectral amplitudes of accelerations or rotational motions as shown in Fig. 7.
The Taipei basin is a triangular-shaped alluvium basin filled with the Quaternary unconsolidated sediments overlying the Tertiary basement (Wang-Lee and Lin, 1987; Chang et al., 1998). Lin (2001) observed that the sediments thicken northwestward from a thin basin margin in the southeast to about 700-m thick sediments in the northwest. The topmost part of sediments is a soft layer, composed of unconsolidated sand, silt and clay with a thickness varying from $50 \mathrm{~m}$ in the southeastern part to $120 \mathrm{~m}$ in northwestern part. Previous studies of site effect in the Taipei basin (e.g., Wen and Peng, 1998; Wang, 2008) showed that high amplifications at low frequencies $(0.2-$ $1 \mathrm{~Hz})$ and at high frequencies $(1-3 \mathrm{~Hz})$ could be correlated, respectively, with the areas of deepest sediments and those near the basin edges, except for a steep basin edge in the west. The TAIPEI 101 skyscraper is located near the eastern margin of the Taipei basin.

The TAIPEI 101 building's TMD with a gross weight of 660 metric tons swayed during the 2005 Typhoon Longwang and the 12 May 2008 Wenchuan, China earthquake from observations and the 2010 Typhoon Fanapi from seismic data (Chen et al., 2012), but it did not sway during the great 2011 Tohoku-Oki earthquake. This is an interesting problem. Long-period strong ground motions caused by large earthquakes are the main factors responsible for seismic damages of large-scale structures, such as high-rise buildings, long bridges and big tank farms (e.g., Koketsu et al., 2005). Chen et al. (2008) analyzed strong ground motions generated by the 26 December 2006 Pingtung offshore twin earthquakes $\left(M_{\mathrm{L}}=6.96\right.$ and 6.99 , respectively) and found that the long-period ground motions were amplified by a factor from 2 to 10 in the Taipei basin and Lanyang basin at the northern end of Taiwan which are about $350 \mathrm{~km}$ 
11-Mar-2011 Tohoku, Japan earthquake Mw9.0

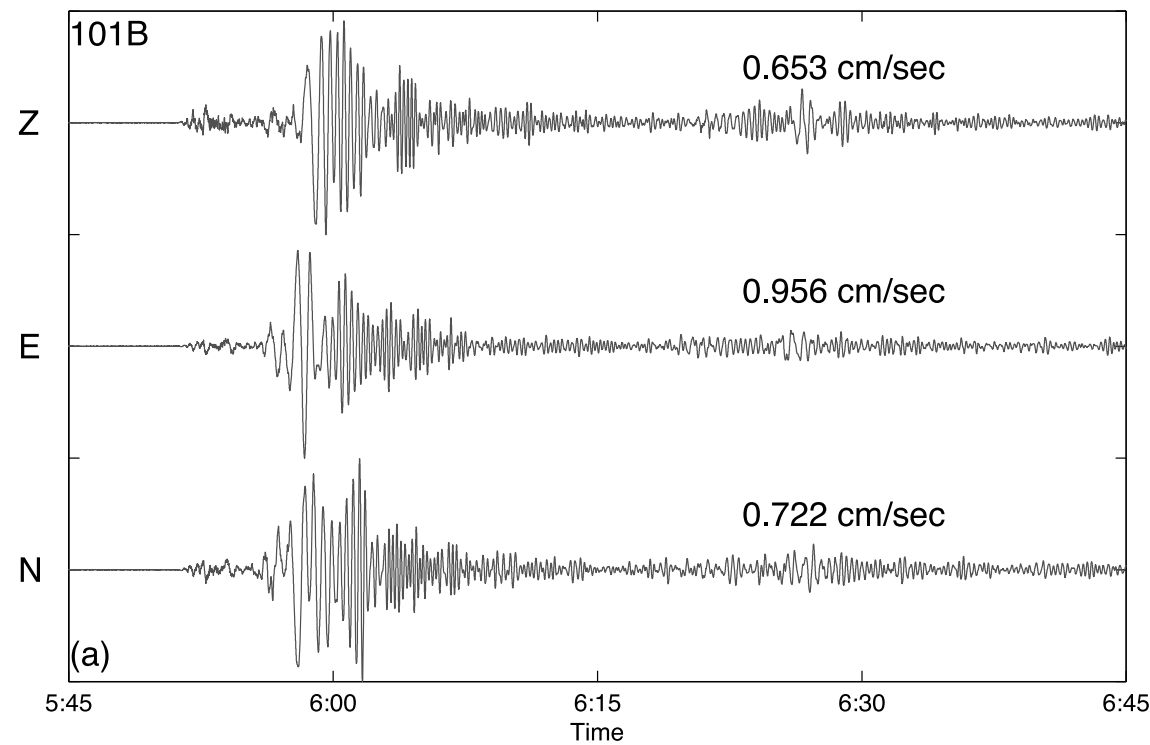

12-May-2008 Wenchuan, China earthquake Mw7.9

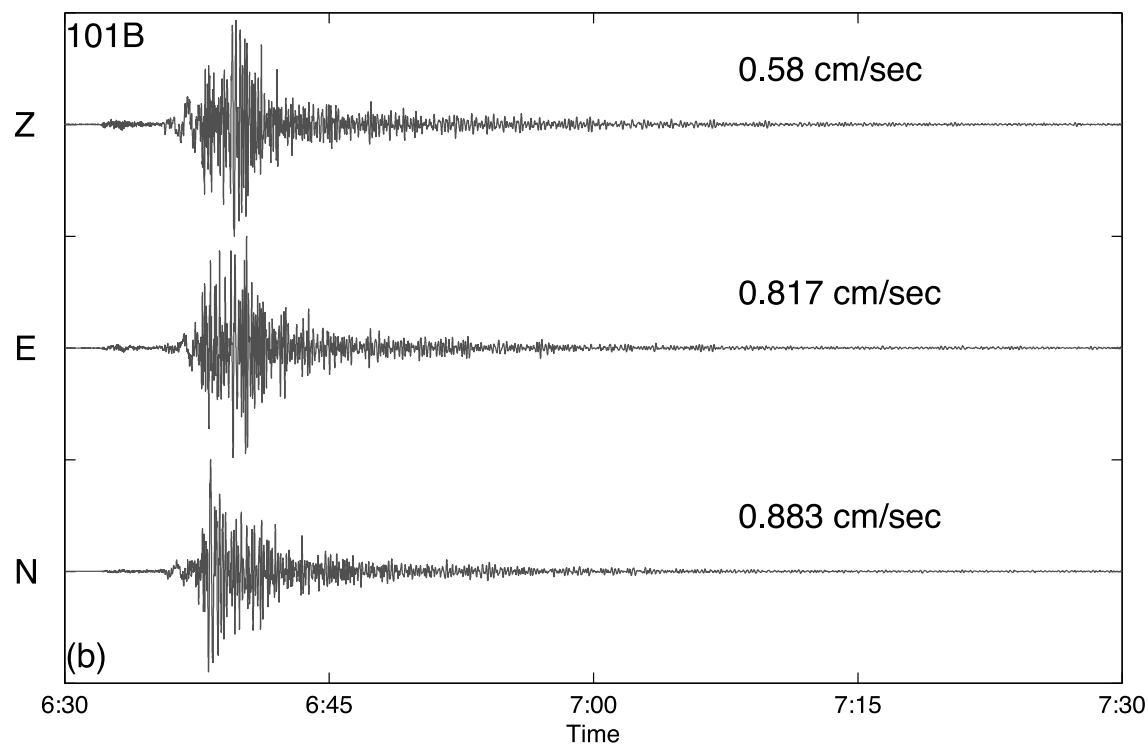

Fig. 8. Three-component seismograms of (a) the 11 March 2011, Tohoku, Japan earthquake and (b) the 12 May 2008 Wenchuan, China earthquake recorded at $101 \mathrm{~B}$

away from the source region. The long-period ground motions generated from the 12 May 2008 Wenchuan, China earthquake, which was about $1910 \mathrm{~km}$ from Taipei, caused a significant resonance in tall buildings in the Taipei basin, and thus some people in a few high-rise buildings felt the vibrations.

Three-component seismograms generated by the 2011 Tohoku-Oki earthquake $\left(M_{\mathrm{w}}=9.0\right)$ and those by the 2008 Wenchuan earthquake $\left(M_{\mathrm{w}}=7.9\right)$ at station 101B are showed in Fig. 8. Obviously, the seismogram of the former shows lower frequency signals than that of the latter. The peak ground velocities (PGV) along the vertical, EW, and NS components are about $0.65,0.96$, and $0.72 \mathrm{~cm} / \mathrm{sec}$, respectively, for the former and about $0.58,0.82$, and 0.88 $\mathrm{cm} / \mathrm{sec}$, respectively, for the latter. Although the maximum PGV of the former is larger than that of the latter, the TAIPEI 101 building's TMD swayed during the latter yet not during the former. This might be caused mainly by the significant difference in frequency contents between the two events.

To compare the long-period ground motions in the Taipei basin generated from the great 2011 Tohoku-Oki earthquake $\left(M_{\mathrm{w}}=9.0\right)$ and the 2008 Wenchuan $\left(M_{\mathrm{w}}=7.9\right)$ earthquake, the acceleration spectra of horizontal component at station 101B generated by the two events are displayed in Fig. 9. The former caused large response in a narrow frequency range of $0.015-0.09 \mathrm{~Hz}$, while the latter resulted in large response in a wider frequency range from 0.06 to $0.6 \mathrm{~Hz}$. In the frequency range from 0.1 to $0.6 \mathrm{~Hz}$, the level of long-period ground motions developed in the Taipei basin from the former was not significant, and about 10 times less than that from the latter. Low ground motions in this frequency range did not push the TMD to move. Such a difference in the level of the long-period ground mo- 


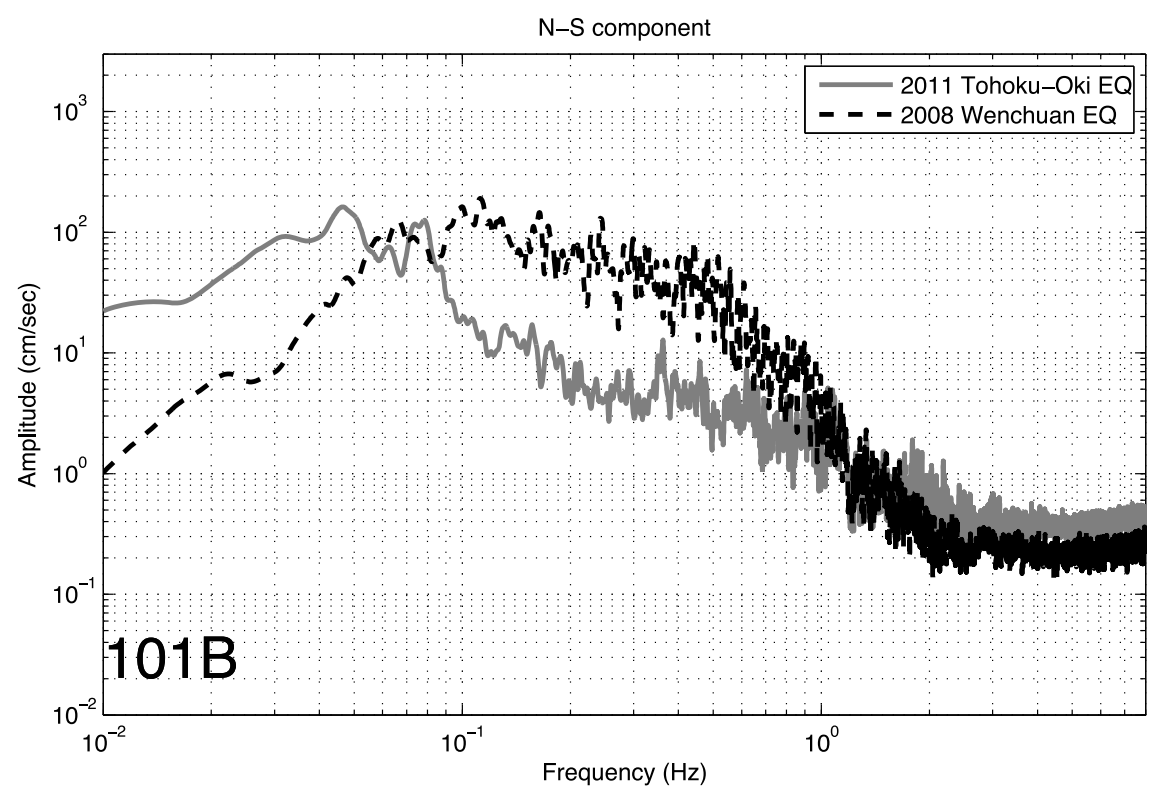

Fig. 9. The NS-component spectral amplitudes from the 11 March 2011, Tohoku, Japan earthquake $\left(M_{\mathrm{w}}=9.0\right)$ and the 12 May 2008 Wenchuan, China earthquake $\left(M_{\mathrm{w}}=7.9\right)$ recorded at $101 \mathrm{~B}$.

tions between the two earthquakes might be due to different earthquake rupture processes, different source radiation patterns or different path effects. A further study should be made to answer the questions in near future.

\section{Conclusions}

This study examined vibrations of the super tall TAIPEI 101 skyscraper located at the Hsinyi district of Taipei, Taiwan caused by the 11 March 2011, Tohoku-Oki, Japan earthquake $\left(M_{\mathrm{w}}=9.0\right)$ from the data recorded at stations on the $74^{\text {th }}$ and $90^{\text {th }}$ floors above ground and the fifth floor underground of a newly installed seismic array inside the building and a nearby downhole station. Fundamental and higher mode vibrations, associated with local peak amplitudes, could be clearly delineated in the spectra. The fundamental-mode frequency is approximately $0.15 \mathrm{~Hz}$, which is the natural frequency for the skyscraper. Spectral ratios on the fifth floor below ground to the downhole station are smaller than 2 when $f<0.3 \mathrm{~Hz}$ and are up to about 10 at $f=\sim 1 \mathrm{~Hz}$. This could be due to amplifications of seismic waves in the soft surface layers. Ratios of spectra at the building to those at the downhole station increase from unity on the fifth floor underground to factors of 110 and 146 , respectively, on the $74^{\text {th }}$ and $90^{\text {th }}$ floors above ground for the fundamental mode.

The skyscraper is equipped with a 660-metric-ton tuned mass damper (TMD) in the main building between the $87^{\text {th }}$ and $91^{\text {st }}$ floors. The TMD is the largest of its type in the world. The TMD swayed during the 2005 Typhoon Longwang, the 12 May 2008 Wenchuan, China earthquake and the 2010 Typhoon Fanapi, but it did not sway during the great 2011 Tohoku-Oki earthquake. The frequency content of accelerograms, recorded on the fifth floor below ground from the great 2011 Tohoku-Oki earthquake, appears mainly in a frequency band of $0.015-0.1 \mathrm{~Hz}$, thus being unable to cause high excitation in the TAIPEI 101 skyscraper.
Acknowledgments. We appreciate two anonymous reviewers for giving us significant comments to improve the article. We thank TAIPEI 101 for providing space and power supply for installation of building array. We appreciate Mr. Jeff Sheu, engineering operation manager of TAIPEI 101, for the assistance in fieldwork. We also thank Mr. Chin-Shang Ku of the Institute of Earth Sciences, Academia Sinica for the assistance in installation and maintenance of TAIPEI 101 building array. This work was supported by the Institute of Earth Sciences, Academia Sinica and the National Science Council, R.O.C. under grant NSC 100-2119-M-001-023.

\section{References}

Aoi, S., T. Kunugi, W. Suzuki, N. Morikawa, H. Nakamura, N. Pulido, K. Shiomi, and H. Fujiwara, Strong motion characteristics of the 2011 Tohoku-oki earthquake from K-NET and KiK-NET, SSA Annual Meeting, 2011.

Chang, H. C., C. W. Lin, M. M. Chen, and S. T. Lu, An introduction to the active faults of Taiwan, Explanatory Text of the Active Fault Map of Taiwan SCALE 1:55000, Central Geol. Surv., MOEA, ROC, 103 pp., 1998 (in Chinese).

Chen, K. C., Strong ground motion and damage in the Taipei basin from the Moho reflected seismic waves during the March 31, 2002, Hualien, Taiwan earthquake, Geophys. Res. Lett., 30(11), 1551, doi:10.1029/2003GL017193, 2003.

Chen, K. C., J. H. Wang, and T. L. Teng, Long-period ground motion observations along two linear profiles from the 26 December 2006 Pingtung offshore earthquakes, Terr. Atmos. Ocean. Sci., 19, 653-669, doi:10.3319/TAO.2008.19.6.653, 2008.

Chen, K. C., J. H. Wang, B. S. Huang, C. C. Liu, and W. G. Huang, Vibrations of the TAIPEI 101 skyscraper induced by the 2010 Typhoon Fanapi, Terr. Atmos. Ocean. Sci., 2012 (accepted).

eentec, $R-1$ Triaxial Rotational Seismometer, St. Louis, Missouri, 2 pp., 2007.

Furumura, T., S. Takemura, S. Noguchi, T. Takemoto, T. Maeda, K. Iwai, and S. Padhy, Strong ground motions from the 2011 off-the Pacific-Coast-of-Tohoku, Japan $\left(M_{w}=9.0\right)$ earthquake obtained from a dense nationwide seismic network, Landslides, 8, 333-338, doi:10.1007/s10346-011-0279-3, 2011.

Haskett, T., B. Breukelman, J. Robinson, and J. Kottelenberg, Tuned mass dampers under excessive structural excitation, Report of the Motioneering Inc., Guelph, Ontario, Canada N1K 1B8, 7 pp., 2003.

Huang, W. G., B. S. Huang, J. H. Wang, K. C. Chen, K. L. Wen, S. Tsao, Y. C. Hsieh, and C. H. Chen, Seismic observations in the Taipei metropolitan area using the downhole network, Terr. Atmos. Ocean. Sci., 21, 615-625, 2010. 
Hutt, C. R., J. R. Evans, and I. Yokai, A brief test of the Tokyo Sokushin VSE-355G3 strong motion velocity seismometer, Open-File Report 2008-1331, U.S. Geological Survey, 44 pp., 2008.

Joseph, L. M., D. Poon, and S. S. Shieh, Ingredients of high-rise design Taipei 101, the world's tallest building, Struct. Mag., 40-45, 2006.

Kinemetrics, User guide: EpiSensor force balance accelerometer, Document 301925, Kinemetrics, Inc., 56 pp., 2002.

Koketsu, K., K. Hatayama, T. Furumura, Y. Ikegami, and S. Akiyama, Damaging long-period ground motions from the $2003 \mathrm{Mw} 8.3$ Tokachioki, Japan, earthquake, Seismol. Res. Lett., 76, 67-73, 2005.

Lee, S. J., B. S. Huang, M. Ando, H. C. Chiu, and J. H. Wang, Evidence of large scale repeating slip during the 2011 Tohoku-Oki earthquake, Geophys. Res. Lett., 38, L19306, doi:10.1029/2011GL049580, 2011.

Lin, C. C., Geology environment of Taipei metropolis, Symp. on Geol. Hazards of Taipei Metropolis, 1-19, 2001 (in Chinese).

Shieh, S. S., C. C. Chang, and J. H. Jong, Structure design of composite super-columns for the Taipei 101 Tower, Proceeding of International Workshop on Steel and Concrete Composite Constructions, National Center for Research on Earthquake Engineering of Taiwan, 8-9 October
2003, 25-33, 2003.

Suzuki, W., S. Aoi, H. Sekiguchi, and T. Kunugi, Rupture process of the 2011 Tohoku-Oki mega-thrust earthquake (M9.0) inverted from strong motion data, Geophys. Res. Lett., 38, L00G16, doi:10.1029/2011GL049136, 2011.

Tsuru, J. and S. Murakami, Summary of the field survey and research on "The 2011 off the Pacific coast of Tohoku earthquake", Technical Note of NILIM No. 647/BRI Research Paper No. 150, 172 pp., 2011.

Wang, J. H., Urban seismology in the Taipei metropolitan area: Review and Perspective, Terr. Atmos. Ocean. Sci., 19, 213-233, 2008.

Wang-Lee, C. M. and T. P. Lin, The geology and land subsidence of the Taipei Basin, Mem. Geol. Soc. China, 9, 447-464, 1987.

Wen, K. L. and H. Y. Peng, Site effect analysis in the Taipei basin: Results from TSMIP network data, Terr. Atmos. Ocean. Sci., 9, 691-704, 1998.

K.-C. Chen (e-mail: chenkc@earth.sinica.edu.tw), J.-H. Wang, B.-S Huang, C.-C. Liu, and W.-G. Huang 